bodies represent a stage in the life cycle of the protozoan organisms described by Dr. Henry Wade and myself as occurring in certain carcinomatous tumours. We had previously observed such rods in the old silver-gold preparations but never in large numbers, and we were unable to attach any significance to them. In sections prepared by the improved ammonia-silver process and decolourised by cyanide these rod-shaped bodies tend to retain the black deposit for a short period subsequent to their development; at a later stage they are much more readily bleached by the cyanide. These preparations reveal in the protoplasm of many of the epithelial cells, especially in carcinatoma of the breast, more or less numerous spherical or oval bodies which were described in previous papers, and from these bodies the rods can be seen to originate. In palladinm methyl violet preparations these globular bodies can also be recognised, often appearing distinctly nucleated, and various stages in their transformation into rods can easily be observed. The evidence of the histological preparations upon this point is confirmed by that derived from an agar culture from a secondarily infected gland in a case of malignant adenoma of the intestine, described by $\mathrm{Dr}$. Wade and myself. This culture contains in the substance of the agar numerous spherical bodies with the staining reactions of those demonstrable in the protoplasm of some carcinoma cells, and the study of preparations of this culture stained by the methyl violet method has revealed the fact that these spheres become transformed into rod-like bodies identical with those that, can be seen in the tissues. In a future paper I hope to deal fully with the subject of the life cycle of these protozoan organisms. If these rods represent merely a single phase in a complicated life cycle, it should be easy to understand how in many carcinomatous tumours they can be found only in small numbers whilst in other tumours of the same kind they are abundant. It seems to me probable from evidence collected that not one species of protozoan organism but several closely allied species are the pathogenic agents in the production of carcinomatous tumours. It at least appears that the forms found in carcinoma of the breast present certain characters which distinguish them from those that may be observed in squamous epitheliomata and in intestinal tumours, although the life cycles are essentially the same.

I have endeavoured to ascertain what becomes of the rods, but as yet only a few facts have come to light. At first it seemed probable that these bodies are motile forms which escape from the cell in which they have originated and which, after travelling some distance, infect other cells, but this hypothesis on being tested has failed to obtain any confirmation. The evidence, indeed, very strongly supports the view that the rods, instead of tending to escape from the cell, seek to penetrate the nuclear membrane and that they undergo a further evolntion within the substance of the nucleus. Not only may the rods frequently be seen to abut apon the nuclear membrane, but they may sometimes be observed to have partially penetrated it, either by movement or by means of end-growth. The occurrence of characteristic rods wholly within a nucleus is quite common and occasionally several may be seen in one nucleus.

In conclusion, I would say that if pathologists will apply the palladiam methyl violet method to a few properly fixed and somewhat recently obtained carcinomata of the breast and squamous epitheliomata, I am confident that they will quickly be able to confirm and to extend these observations which I have here briefly recorded. I have to express my indebtedness to Mr. F. M. Caird, Mr. David Wallace, and Dr. M. B. Hannay for most of the tissues used in these investigations.

The palladium methyl violet method. - The reagents required are saturated solution of palladium chloride in 1 per cent. citric acid in water, 1 per cent. solution of methyl violet $6 \mathrm{~B}$ or $5 \mathrm{~B}$, saturated solution of iodine in 2.5 per cent. potas. sium iodide, equal parts of turpentine and benzole, equal parts of pure anhydrous aniline oil and benzole, benzole and benzole balsam. The tissues should be fixed in 5 per cent. formalin in $\frac{3}{4}$ per cent. salt solution (and preserved in the same fluid or in alcohol), or for 24 hours in Heidenhain's sublimate solution, with subsequent removal of the mercury by means of iodine in the usual way. Cat thin sections by the dextrine freezing method. Place the sections overnight in the palladium solution. Wash them in three changes of water and then place them for from 10 to 20 minutes in the methyl violet stain. Wash the sections shortly in water and transfer them to the iodine solntion, in which they should remain for from 10 to 20 minutes. Next transfer the sections to a bowl of water. In this they may be left for an hour or longer without suffering harm. Steel needles must not be used in these operations. Take a section $\mathrm{np}$ from the water upon a perfectly clean slide. Carefully remove water from around it by means of a towel. Next lay the slide upon the table and with a piece of smonth blotting or filuer paper (folded double) blot the section in the same manner as one dries a sheet of wet manuscript. Immediately afterwards, without allowing it to dry completely in air, pour over the section some drops of a mixture of equal parts of turpentine and benzole. Renew this turpentine-benzole after a few seconds and then place the slide upon the heater (described below), where it must remain at a temperature of about $60^{\circ} \mathrm{C}$. until completely dehydrated. If the turpentine-benzole tends to evaporate off the section add more by means of a pipette. When dehydration is complete the previously black and opaque tissue assumes a dark blue and faintly translucent appearance. Generally from 15 to 20 minutes are required. When the section seems dehydrated remove the slide from the heater, allow it to cool, and then pour off the turpentine-benzole. Decolourise with aniline-benzole. Renew this two or three times. Avoid breatbing on the slide as the smallest trace of moisture in the aniline-benzole will cause complete decolourisation of the section. When the dye ceases to come away wash the section in several changes of pure benzole and mount in balsam in benzole. It is essential that the section should be completely dehydrated on the heater. Any spot in which moisture has been allowed to remain will be decolourised by the aniline-benzole. A heating apparatus of a very simple form is sufficient for the purposes of this method. I use a small spirit lamp placed below a tripod stand, on the top of which there is a thin metal plate, and upon this again two small iron bars laid parallel to each other and at such a distance as just to allow the two ends of microscopic slide to rest upon them. By such an arrangement heat is transmitted only by the two ends of the slide and the turpentine benzole is driven to the centre. Tissues that have been in alcohol or in formalin for over two years do not, as a rule, stain deeply enough, and must then be regarded as unsuitable for the application of this method.

\section{ON THE RELATIONSHIP OF CANCER CELLS TO THE DEVELOPMENT OF CANCER.}

BY J. E. SALVIN-MOORE, A.R.C.S., F.L.S., F.Z.S., PROFFSSOR OF EXPERIMENTAL AND PATHOLOGICAL CYTOLOGY AND DLRECTOR OF THE CANCER RESEARCH LABORATORIES, UNIVEBSITY OF LIVERPOOL; AND

\section{O. 18. WALKER,}

ASSISTANT DIRECTOR OF THE CANCER RESEARCH LABORATORIES, UNIVERSITY OF LIVERPOOL; AND HONORARY LECTURER IN CYTOLOGY IN THE LIVERPOOL SCHOOL OF

$$
\text { TROPICAL MEDICINE. }
$$

Is the present communication we wish to record some observations made in the Cancer Research Laboratories, University of Liverpool. The observations in question relate to the propagation of cancer in mice. The tumours utilised are derived from a growth originating sporadically in a mouse, and most generously placed at the disposal of the Liverpool Cancer Research Committee by Professor Ehrlich of Berlin. The tumours upon which these observations have been made are of exceptional virulence. They are graftable from one mouse to another-that is to say, if small fragments of the growth be removed from an animal these fragments will grow when placed under the skin of a healthy individual. So far as can be ascertained from purely cytological examination of the process, the new tumour in inoculated mice appears to proceed directly from the cells belonging to the original tumour which have been mechanically transferred. The grafted tumour, in fact, apparently arises from the implanted cells, and not through any alteration of the tissues of the new host which surround the graft.

For purposes of investigation portions of these tumours were removed from mice and subjected for periods of from 
20 minutes to half an hour to the action of liquid air. They were then at once introduced into healthy mice beneath the skin, the presumption being that in these circumstances the tumour cells would be destroyed by the action of the liquid air, and consequently that they would multiply no further. However, among the inoculations made with the frozen material it was found that in some cases new tumours were produced. Further, in a number of mice wherein tumours of the same strain were already growing similar inoculations were made in a remote part of the body in some of these also the same positive result was obtained. From these observations it is rendered clear that exposure to liquid air at a temperature of about $-195^{\circ}$ does not necessarily destroy the potentiality of the substance of a mouse tumour to produce fresh tumours of the same kind in mice into which such frozen tumour substance has been grafted.

These facts in themselves are somewhat surprising, and they immediately raise a number of questions which it will be desirable to have elucidated in the interests of research concerning the nature of cancer. In the first place, it is rendered clear that exposure to liquid air for a certain period of time does not destroy the principle apon which the vitality of mouse cancer depends. If, as may be the case, the cells composing the mass of the tumour, and constituting the grafts, are killed by exposure to liquid air, then the development of mouse cancer after such exposure indicates not merely that the growth of similar tumours is independent of the integrity of the "cancer cells," but also that the new tissues are not necessarily formed from the implanted cells at all, and may arise from the cells of the new host in response to some stimulus introduced along with the frozen material, and quite independent of the integrity of the socalled "cancer cells."

This matter is at present engaging our attention, but the fact that the capacity for originating new growths is not necessarily destroyed in the substance of tumours after exposure to liquid air, certainly suggests that the production of new tumours in the hosts into which the frozen cancer tissue has been introduced may possibly not be dependent upon the introduction of the "cancer cells" at all, but upon the action of a virus which is independent of these cells, and retains its activity after being subjected to the temperature of liquid air. It is well known that a number of bacteria are not killed by this temperature. The fact that cancer can be originated in mice by implantation of portions of frozen tumours may indicate that there exists some such cause as an organised irritant or paracite acting as an agent in the production of cancer On the other hand, however, it is not yet certain that the cells from the tumour introduced into a new individual are killed by half an hour's exposure to the temperature of liguid air, particularly as the seeds of some plants and trypanosomes are said to survive this temperature.

\section{NOTE UPON THE EFFECT OF LIQUID AIR UPON THE GRAFTABLE CANCER OF MICE.}

BY J. E SALVIN-MOORE, A.R.C.S., F.L S., F.Z S., PROFESSOR OF EXPERIMENTAL AND PATHOLOGICAL CYTOLOGY AND DIRECTOR OF THE CANCER RESEARCH LABORATORIES, UNIVERSITY OF IIVERPOOL;

$A N D$

J. O. WAKELIN BARRATT, D.So., M.D. LOND., F.R C.S. ENG.

Is the present communication we wish to record some observations made upon the graftable tumours of mice. The tumours under observation were obtained for the Liverpcol Cancer Research Laboratories, through the kindness of Professor Bang of Copenhagen, and were received originally from Professor Jensen. For purposes of certain experiments not yet completed fragments of the tumour in question were placed in liquid air for from 20 minutes to half an hour and after thawing were placed under the skin of fresh mice in the ordinary way. It was presumed that by exposure to the temperature of liquid air the tumour cells would be immediately killed. However, in a number of such grafts after a period of from ten to 20 days fresh tumours appeared at the site of the inoculations.
These observations appear to be of interest in themselves ; but more especially so because they lead up to a number of important questions. It seems to be probable from what has been observed in relation to healthy skin that exposure to the temperature in liquid air rapidly kills the cells composing it. It may, of course, be that cancer cells differ in their capacity to resist such a temperature, but at the same time since some bacteria and other organisms are known not to be killed by the temperature in question it is clearly suggested that there may be an organism in or among the cancer cells able to withstand the treatment to which they have been subjected and afterwards consequently capable of setting up the formation of a tumour derived from the tissues of a new host. These are, however, matters which are engaging our attention and at present it is undesirable to say more concerning them.

\section{TREATMENT OF GRAVES'S DISEASE WITH THE MILK OF THYROIDLESS} GOATS.

By WALTER EDMUNDS, M.A., M.C. Cantab., F.R.C.S. ENG.,

SURGEON TO THE PRINCE OF WALES'S HOSPITAL, TOTTENHAM.

SINCE the discovery of the nature of myxoedema it has been thought that the symptoms of Graves's disease are due to an excessive secretion from the enlarged thyroid gland Further, it has been thought that a remedy might be found in the serum or milk of thyroidless animals, the idea being that to counteract the thyroid secretion the normal body secretes an antithyroidin, and that in thyroidless animals this antithyroidin would be in excess and available to act as an antidote to the excess of thyroid secretion in Graves's disease.

There are, however, some difficulties in the way of this theory. The severity of the symptoms of Graves's disease is by no means always in proportion to the size of the goitre, nor is this always one of the first symptoms ; indeed, from the history of the cases it would seem that they often start from some mental strain. Another difficulty arises from the fact that myxœedema and Graves's disease sometimes coexist. Babinski mentions two such cases and Dr. Samuel West has recently recorded a very clear case occurring under his care at St. Bartholomew's Hospital.

A third difficulty arises from the symptoms produced by the excision of the thyroid varying in different animals. In dogs and cats the operation produces severe nervous symptoms, tremors, paralysis, and convulsions, quickly followed by death. In goats, on the other hand, as a rule no ill effects follow. I have recently performed the operation on ten goats. One of them was young and not fully grown; the effect of the operation was that it ceased to grow and became in fact a cretin. The other nine goats were fully grown and in seven of them the operation produced no effect; in the other two there came on after some montbs a swelling of the face, due no doubt to myxodema; this was treated with thyroid tabloids and disappeared but both animals died. A small percentage of the doga submitted to complete thyroidectomy escape the acute symptoms; they then remain well; they do not later develop myxœdema nor does this occur in those dogs in which nearly the whole of the thyroid gland is removed and one or more parathyroids are left. Thus dogs do not have myzodema and goats do not have the acute nervous symptoms which occur in dogs and which are attributed by Gley and others to the removal of the parathyroid glands. Monkeys, however, which are nearer to man than either dogs or goats, may have aparathyroidea or myxœedema or both. As a rule, it seems that monkeys when submitted to thyroidectomy die from the nerve symptoms; those, however, which survive or escape this may have, and some do have, myxœ lema.

Thus, even if it is admitted that the symptoms of Graves's disease are due to the thyroid secretion, the question may not be merely one of too much or too little, but we may have to distinguish between the secretion from the thyroid proper and that from the parathyroids.

A fourth, and last, objection to the theory is that it leaves out of account the possibility of any action of the central nervous system on the secretion of the gland. Fixner, and later myself, have shown reason for thinkirg that there is 